УДК 37

\title{
ВЗАИМОДЕЙСТВИЯ УЧАСТНИКОВ \\ ОБРАЗОВАТЕЛЬНОГО ПРОЦЕССА ПРИ ОРГАНИЗАЦИИ ДИСТАНЦИОННОГО ОБРАЗОВАНИЯ НА ОСНОВЕ НЕПРЕРЫВНОГО ОБУЧЕНИЯ ШКОЛЬНИКОВ
}

\begin{abstract}
Пайгильдина Маргарита Геннадьевна студентка магистратуры Научный руководитель: Ахметжанова Галина Васильевна доктор педагогических наук, профессор заведующий кафедры педагогики и методик преподавания ФГБОУ ВО Тольяттинский государственный университет
\end{abstract}

Аннотация: статья раскрывает особенности взаимодействия участников образовательного процесса при организации дистанционного образования на основе непрерывного обучения. Участниками данного вида деятельности становятся обучающиеся, которые отсутствуют в школе. Авторами проведен анализ посещаемости школьников, актуализирован процесс внедрения активных форм обучения. В статье представлены рекомендации по организации дистанционного урока, описана деятельность учителя, ученика, родителей на каждом этапе внедрения в учебный процесс активных форм обучения.

Ключевые слова: дистанционное образование, непрерывное обучение, взаимодействие участников образовательного процесса, учитель, ученик, родители, качество знаний, подготовительный этап, организационный этап, обучение, контроль.

\section{INTERACTION BETWEEN THE PARTICIPANTS OF THE EDUCATIONAL PROCESS IN THE ORGANIZATION OF DISTANCE EDUCATION ON THE BASIS OF LIFELONG LEARNING OF SCHOOLCHILDREN}

Paygildina Margarita Gennadievna Scientific adviser: Akhmetzhanova Galina Vasilievna

\begin{abstract}
The article reveals the features of interaction between the participants in the educational process in the organization of distance learning on
\end{abstract}


the basis of lifelong learning. Participants of this type of activity are students who are not in school. The authors analyzed the attendance of schoolchildren, updated the process of implementing active forms of learning. The article presents recommendations on the organization of a distance lesson, describes the activities of a teacher, a student and parents at each stage of the introduction of active forms of learning into the educational process.

Key words: distance education, lifelong learning, interaction of participants in the educational process, teacher, student, parents, quality of education, preparatory stage, organizational stage, education, control.

Современная система образования создает условия для непрерывного обучения посредством реализации основных образовательных программ, обеспечивает общедоступность. Используются различные образовательные технологии, в том числе дистанционное, электронное обучение. В статье 16 закона об образовании говорится: «При реализации образовательных программ с применением исключительно электронного обучения, дистанционных образовательных технологий в организации, осуществляющей образовательную деятельность, должны быть созданы условия для функционирования электронной информационно-образовательной среды»[1]. В период пандемии организация дистанционного обучения позволила реализовать выполнение образовательных программ в полном объеме независимо от места положения обучающихся. Сложно говорить о качестве образования в этот период, т.к. современное образование не готово к внедрению самообразования начиная со школьного возраста. Отрицание действительности приводит к деградации общества, нежеланию развиваться и со стороны родителей, и со стороны детей.

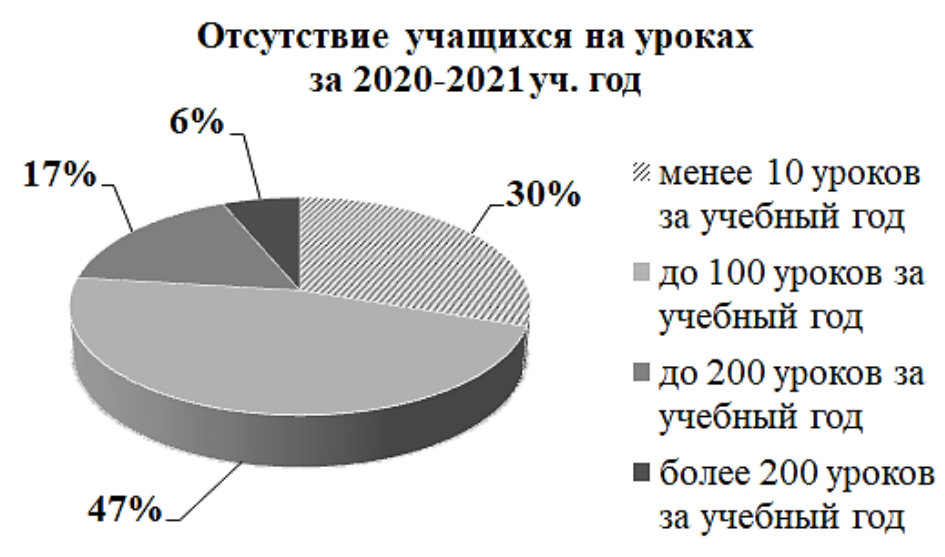

Рис. 1. Анализ посещаемости учащимися уроков за учебный год 
Во время учебного процесса учащиеся отсутствуют на уроках по уважительной причине: болезнь, соревнования. Анализ посещаемости уроков за учебный год (рис.1) показывает, что 30\% пропускают менее 100 уроков, $47 \%$ - до 100 уроков, $17 \%$ - от 100 до 200 уроков, $6 \%$ - более 200 уроков.

Опрос родителей показывает, что контроль выполнения заданий и самоподготовка по новой теме осуществляется. Учащиеся изучают материал с близкими, используют Интернет ресурсы, 30\% детей выполняют задания самостоятельно. Только $27 \%$ родителей могут объяснить и рассказать материал по предмету, остальные или не знают, или нет времени. Работа с неуспевающими детьми в настоящее время проводится во внеурочное время как знакомство с новым материалом, где отсутствует важный этап урока «закрепление материала».

Как организовать качественное предоставление образовательных услуг для учащихся, которые отсутствуют в школе? Участвовать в решении данной проблемы надо каждому участнику образовательного процесса. 72\% родителей согласны на применение дистанционного, электронного урока в период отсутствия их детей в школе. Важно чтобы было:

- аудио и видео объяснение, что необходимо выполнить в течение урока;

- использование интерактивных заданий с возможностью самопроверки;

- наличие образца классной работы;

- обратная связь с учителем.

Е.С. Полат, М.Ю. Бухаркина и М.В. Моисеева отмечают, что в результате внедрения в учебный процесс современных образовательных технологий преподаватель становится консультантом. Освоение новой функции консультирование, сопровождение - требует специальной психологопедагогической подготовки [2].

Цифровая образовательная среда дает принципиально новые возможности: перейти от обучения в классной комнате к обучению в любом месте и в любое время; проектировать индивидуальный образовательный маршрут, тем самым удовлетворять образовательные потребности личности обучающегося; превратить обучающихся не только в активных потребителей электронных ресурсов, но и создателей новых ресурсов и др. [3]

Организация обучения детей с применение активных форм обучения в дистанционном образовании включает в себя подготовительный этап, 
организационный этап, обучение и контроль (рис.2).

В период подготовительного этапа учитель составляет план урока, каждый элемент которого размещает в информационно-образовательной среде, используя технологии web 2.0 ; родители организуют образовательное пространство в домашних условиях, в котором обязательно наличие учебных принадлежностей и технических устройств для организации электронного, дистанционного обучения (компьютер или планшет с выходом в Интернет, наличие гарнитуры и веб-камеры).

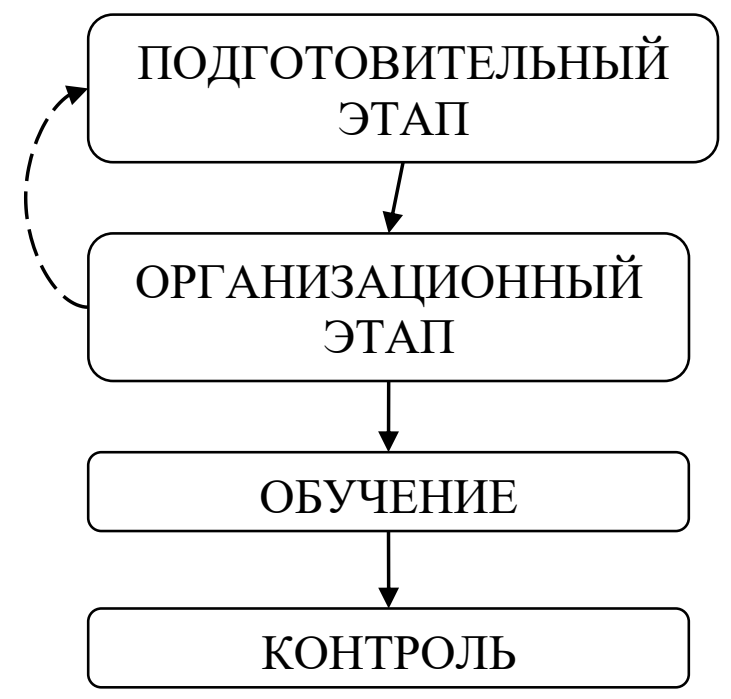

Рис. 2. Схема организации дистанционного, электронного урока

Во время организационного этапа педагог:

- отправляет электронное уведомление родителям и детям о дате и времени проведении занятия;

- размещается в информационном пространстве график онлайнконсультаций, которые ориентированы на решение вопросов об организации и проведении дистанционных уроков;

- проверяет работоспособность электронных ресурсов, которые необходимы для проведения урока. Вводит корректировку в план урока, размещенные информационные ресурсы.

На этапе «Обучение» ученик выполняет задания электронного урока: просмотр видеообъяснения по новой теме, повторение ранее изученного материала с помощью интерактивных заданий, выполнение классной работы по учебнику или самостоятельной работы, рефлексия. Проверка работы на уроке осуществляется учащимся или родителями по предоставленному 34 
образцу учителем. Дети приобретают навыки самоанализа и самоконтроля, развивается ответственность к практико-ориентированной деятельности.

В период внедрения активных методов обучения в дистанционном образовании проводились беседы с родителями и детьми. Вопросы были связаны с работоспособностью информационного ресурса, с последовательностью выполнения заданий.

На этапе контроля учитель проверяет самостоятельную работу, тесты, анализирует рефлексию и предоставляет результаты родителям и учащимся через электронный дневник.

На сайте «В мире математики»[4] представлены электронные уроки, проведенные в МБУ «Школа №75» среди учащихся 5-ых классов. Положительные результаты внедрения данного подхода прослеживаются при обязательном наличии видеообъяснения теоретического материала и выполнения заданий, беседы с родителями и учащимися с целью решения организационных вопросов, своевременного контроля деятельности учащихся, выполнения заданий урока по предоставленному плану деятельности, своевременного взаимодействия участников образовательного процесса.

Результат образовательной деятельности зависит от учителя, ученика и родителей не зависимо от формы и методов организации работы. Своевременное взаимодействие каждого в период отсутствия ребенка в школе позволит организовать дистанционное обучение, контролировать качество знаний. Разработанные электронные уроки целесообразно применять для повторения материала и для работы со слабоуспевающими детьми. В этом случае ученик просматривает видеообъяснения теоретического материала и решения заданий неограниченное количество раз, самостоятельно формулирует вопросы по изучаемой теме, беседует с учителем.

Родители должны воспитывать в себе и своих детям положительное отношение к информационно образовательной среде, пользоваться Интернет ресурсами для обучения, поиска и получения информации. Добиться данных результатов можно только при правильной организации дистанционного урока, в котором учитель становится консультантом. Он направляет деятельность учащихся, контролирует их, беседует с родителями.

Взаимодействие участников образовательного процесса при проведении дистанционных, электронных уроков для учащихся, которые отсутствуют в школе, позволит создать условия для организации непрерывного обучения, контролировать качество знаний. Что в результате дает возможность достойно 
сдать экзамены, для поступления в учебные заведения среднего и высшего профессионального образования.

\section{Список литературы}

1. Федеральный закон "Об образовании в Российской Федерации" от 29.12.2012 N 273-Ф3 // Консультант плюс [Электронный ресурс]. - Режим доступа: http://www.consultant.ru/document/cons_doc_LAW_140174/ (дата обращения: 03.06.2021).

2. Ахметжанова Г. В. Особенности деятельности педагога в условиях дистанционного обучения / Г. В. Ахметжанова, Д. Р. Абиева // Азимут научных исследований: педагогика и психология. - 2019. - Т. 8. - № 3(28). - С. 28-31. DOI 10.26140/anip-2019-0803-0005.

3. Ахметжанова Г. В. Цифровые технологии в образовании / Г. В. Ахметжанова, А. В. Юрьев // Балтийский гуманитарный журнал. - 2018. - T. 7. - № 3(24). - C. 334-336.

4. В мире математики: [Электронный pecypc]. URL: https:// sites.google.com/site/mathsmby75. (Дата обращения: 09.06.2021).

() М.Г. Пайгильдина, 2021 